\title{
NARRATIVA E TRAJETÓRIA CAMPONESA: ESTUDO DE CASO EM UM CURSO DE LICENCIATURA EM EDUCAÇÃO DO CAMPO ${ }^{1}$
}

\author{
NARRATIVE AND PEASANT TRAJECTORY: A CASE STUDY IN A RURAL EDUCATION DEGREE
}

NARRATIVA Y TRAYECTORIA CAMPESINA: ESTUDIO DE CASO EN UN CURSO DE LICENCIATURA EN EDUCACIÓN DEL CAMPO

\author{
SANTOS, Marcelo Loures dos² \\ SILVA, Diego Gonzaga Duarte da ${ }^{3}$
}

\begin{abstract}
RESUMO
As Licenciaturas em Educação do Campo (LEdoCs) formam educadores para atuarem em espaços educativos escolares e não escolares. Organizam-se pela Alternância Educativa, articulando atividades na universidade e na comunidade de seus educandos. Esta pesquisa realizou três entrevistas com uma educanda sobre seus territórios educativos. Tinha por objetivo avaliar as contribuições da Metodologia das Produções Narrativas (MPN) como uma estratégia pedagógica para o desenvolvimento de processos educativos no âmbito de uma LEdoC. Concluiu-se que a MPN favorece uma leitura concreta do campo, produzindo reflexões e sínteses sobre as identidades, trajetórias e escolhas da educanda, apresentando-se como uma estratégia promissora para o processo formativo das LEdoCs.
\end{abstract}

Palavras-chave: Metodologia das Produções Narrativas. Alternâncias Educativas. Educação do Campo.

\section{ABSTRACT}

The Degrees in Rural Education (LEdoCs) train educators to work in school and non-school educational places. They are organized by the Alternating Formative processes, articulating activities in the university and in the community of its students. This research conducted three interviews with a student about its educational territories. The objective was to evaluate the contributions of the Narrative Production Methodology (NPM) as a pedagogical strategy for the development of educational processes within the scope of an LEdoC. It was concluded that the NPM favors a concrete reading of the field, producing reflections and syntheses on the identities, trajectories and choices of the student, presenting itself as a promising strategy for the formative process of The LEdoCs.

Keywords: Methodology of Narrative Production. Alternating Formative Processes. Rural Education.

\section{RESUMEN}

Los Grados en Educación de Campo (LEdoCs) capacitan a los educadores para trabajar en espacios educativos escolares y no escolares. Están organizados por la Alternancia Educativa, articulando actividades en la universidad y en la comunidad de sus estudiantes. Esta investigación llevó a cabo tres entrevistas con una estudiante sobre sus territorios educativos. El objetivo era evaluar las contribuciones de la Metodología de Producción Narrativa (MPN) como estrategia pedagógica para el desarrollo de procesos educativos dentro de un LEdoC. Se concluyó que el MPN favorece una lectura concreta del campo, produciendo reflexiones y síntesis sobre las identidades, trayectorias y opciones del estudiante, presentándose como una estrategia prometedora para el proceso formativo de los LEdoCs.

Palabras clave: Palabras clave: Metodología de las Producciones Narrativas. Alternancia Educativas; Educación del Campo.

\footnotetext{
${ }^{1}$ Pesquisa financiada com recursos da FAPEMIG, processo APQ-01172-15.

2 Universidade Federal de Ouro Preto - UFOP - Mariana - MG - Brasil.

${ }^{3}$ Universidade Federal de Viçosa - UFV - Viçosa - MG - Brasil.
} 


\section{INTRODUÇÃO}

Os cursos de Licenciatura em Educação do Campo, distribuídos entre as diversas Instituições de Ensino Superior brasileiras, realizam a formação continuada para educadores do campo. A atuação desses educadores deve articular os processos educativos vivenciados no meio escolar aos experienciados por seus alunos em suas comunidades de origem (MOLINA; SÁ, 2011). É por meio do processo formativo em alternância, organizado entre atividades desenvolvidas nas Instituições de Ensino Superior (Tempo Escola) e nas comunidades e territórios educativos dos educandos (Tempo Comunidade), que se busca a articulação dessas experiências.

Nesse processo formativo, um dos objetivos do regime de alternância das LEdoCs é criar estratégias, a partir da articulação universidade/comunidade/território e da dialética entre teoria e prática, para que os educandos consigam refletir e intervir sobre as dinâmicas sociais existentes nos meios sociais em que vivem (MOLINA; ANTUNES-ROCHA, 2014). Sob essa perspectiva, a alternância desenvolvida nas LEdoCs tem como princípio auxiliar os educandos do curso a se inserirem nas dinâmicas sociais existentes em seus territórios para desenvolver processos educativos coletivos, envolvendo suas famílias e comunidades em parceria com as organizações sociais e sindicais camponesas (CARVALHO; SILVA, 2018).

Por outro lado, Carvalho e Silva (2018) ressaltam que um dos desafios do regime de alternância em algumas LEdoCs é articular os processos formativos dos Tempos Escola aos processos formativos dos Tempos Comunidade. Estes desafios decorrem da ausência do acompanhamento dos Tempos Comunidades pelos educadores dos cursos e pela complexidade das dinâmicas sociais vivenciadas pelos educandos em suas comunidades e territórios educativos. Assim, busca-se criar estratégias capazes de promover tal articulação, contribuindo para o desenvolvimento de um processo formativo que se integre às lutas, às culturas, às formas de trabalho e às dinâmicas sociais dos povos do campo.

A partir do contexto apresentado, a matriz curricular das LEdoCs deve desenvolver metodologias de trabalho que favoreçam o reconhecimento da complexidade inerente aos contextos sócio-históricos dos seus educandos (MOLINA, 2017). Nessa perspectiva, este artigo tem por objetivo avaliar as possíveis contribuições da Metodologia das Produções Narrativas (MPN) enquanto estratégia pedagógica para o desenvolvimento dos processos educativos no âmbito das LEdoCs. Considera-se que ao narrar se problematiza, se transforma e atua sobre uma agenda sociopolítica de identidades marginalizadas articulando contextos biográficos, históricos e sociais dos sujeitos (GUZMAN; MONTENEGRO, 2014).

A MPN, conforme proposta de Balasch e Montenegro (2003), fundamenta-se na perspectiva dos Conhecimentos Situados ao considerar que todo indivíduo, ao narrar, parte de uma perspectiva parcial sobre as realidades em que vive, permitindo-lhe evidenciar as especificidades culturais, os processos educativos e as práticas sociais existentes nos contextos sociais investigados. Desta maneira, espera-se que a MPN, utilizada como uma estratégia pedagógica para a realização do Projeto de Estudo Temático (PET), possa auxiliar os educandos das LEdoCs a refletirem sobre a realidade vivenciada, construindo interpretações e o encadeamento de eventos micro e macro histórico-políticos 
em suas comunidades. Assim, estariam mais aptos a propor ações para as melhorias que se fizerem necessárias nos territórios em que vivem, cumprindo um dos objetivos dos processos formativos em alternância.

Reconhecendo a necessidade de promover estratégias que articulem os contextos sociais vivenciados pelos educandos aos processos de formação das LEdoCs, o presente artigo avalia a utilização da MPN como atividade vinculada à realização de um dos PETs do curso de Licenciatura em Educação do Campo da Universidade Federal de Viçosa (Licena), o qual tem como tema "Produção de Conhecimento e Qualidade de Vida". Em termos metodológicos, o artigo aborda um estudo de caso, constituído por três entrevistas narrativas realizadas com uma educanda da Licena, buscando identificar e aprofundar as experiências educativas vivenciadas por ela em seu território. Ao término de cada entrevista, a educanda redigia sua narrativa e a enviava à equipe de pesquisadores. Após avaliar cada narrativa enviada, a equipe de pesquisadores formulava questões à educanda. Na primeira narrativa enviada, as questões formuladas buscaram promover e ampliar reflexões na educanda sobre sua trajetória de vida. $\mathrm{Na}$ segunda narrativa enviada, as questões buscavam aprofundar aspectos relacionados aos contextos sociais em que a participante da pesquisa se inseria e os processos de geração de conhecimentos vivenciados em seu território educativo. Na última, as questões ampliaram as discussões da narrativa anterior, aprofundando e problematizando as especificidades dos espaços de produção de conhecimento e dos sujeitos presentes no território educativo da educanda.

Assim, situando-se como um estudo de caso que analisa as contribuições da MPN como estratégia pedagógica para a realização de um dos PETs da Licena, o presente artigo está organizado em quatro seções, além desta introdução. Na primeira, foram destacados os processos de formação em alternância nas LEdoCs, apresentando os contextos históricos que possibilitaram a sua constituição; na segunda, foram evidenciadas as características da MPN, apresentando seus objetivos e as etapas a serem realizadas ao longo do processo de investigação; na terceira, partindo de fragmentos das narrativas elaboradas pela participante da pesquisa, foi avaliado como a MPN foi utilizada para produzir conhecimentos sobre seus territórios educativos; e na última seção, foram apresentadas as considerações finais.

\section{A FORMAÇÃO NOS CURSOS DE LICENCIATURAS EM EDUCAÇÃO DO CAMPO}

Nos últimos anos, as lutas e reivindicações dos movimentos sociais e sindicais camponeses por melhorias na educação para os povos do campo garantiram o desenvolvimento de políticas públicas específicas para a formação de educadores do campo, como o Programa Nacional de Educação na Reforma Agrária (Pronera) e o Programa de Apoio à Formação Superior em Licenciatura em Educação do Campo (Procampo) (MOLINA; ANTUNES-ROCHA, 2014).

O Procampo, programa criado em 2006, destacou-se ao propor a criação das LEdoCs com o intuito de promover a formação de educadores para atuação nos Anos Finais do Ensino Fundamental e Ensino Médio das escolas de educação básica do campo (SANTOS, 2012). As primeiras LEdoCs iniciaram suas atividades em 2007, com experiências pilotos em quatro Universidades Federais indicadas pelos movimentos sociais e sindicais camponeses: Universidade de Brasília, Universidade 
Federal de Minas Gerais, Universidade Federal da Bahia e Universidade Federal de Sergipe (MOLINA; ANTUNES-ROCHA, 2014; MOLINA, 2015).

As experiências desenvolvidas nessas quatro universidades orientaram a construção dos Editais Públicos nos anos de 2008 e 2009, por intermédio da Secretaria de Educação Continuada, Alfabetização, Diversidade e Inclusão (Secadi), possibilitando a ampliação da oferta das LEdoCs para 30 outras Instituições de Ensino Superior no Brasil (MOLINA \& SÁ, 2012). Com a incorporação do Procampo ao Programa Nacional de Educação do Campo (Pronacampo), em 2012, é publicado o edital MEC/SESU/SETEC/SECADI n. ${ }^{\circ}$ 02/2012, ampliando para 42 o número de LEdoCs, distribuídas nas regiões Sudeste, Centro-Oeste, Nordeste, Norte e Sul do Brasil (MOLINA, 2015).

As LEdoCs inauguram uma modalidade de graduação que promove a formação inicial de educadores do campo para "uma atuação profissional que vai além da docência, que tenham condições de trabalhar também na gestão dos processos educativos que acontecem na escola e no seu entorno" (MOLINA; SÁ, 2011, p. 36). Em suas análises, Molina e Sá (2011) destacam que as LEdoCs buscam desenvolver metodologias que integrem as atividades acadêmicas aos contextos sociais dos povos do campo, contribuindo para que os futuros educadores desenvolvam práticas pedagógicas articuladas às lutas dos movimentos sociais e sindicais que atuam com os povos do campo. Para isso, é necessário um modelo de formação que possibilite aos educadores o desenvolvimento de uma atuação profissional articulada aos processos educativos escolares e não escolares, integrando dimensões da vida cotidiana à vida escolar.

Para tanto, os processos formativos no âmbito das LEdoCs ocorrem em regime de alternância, dividindo os tempos e espaços de formação entre Tempo Escola (TE) e Tempo Comunidade (TC) (MOLINA; ANTUNES-ROCHA, 2014). O Tempo Escola é o período no qual os educandos se encontram nas Instituições de Ensino Superior, assistindo aulas, recebendo orientações, relatando experiências e desenvolvendo atividades de ensino, pesquisa e extensão de naturezas diversas; enquanto que o Tempo Comunidade é o período em que se busca articular as atividades acadêmicas com suas atividades agrícolas, de militância nos movimentos sociais e sindicais, de atuação nas escolas do campo, dentre outras atividades realizadas em suas comunidades e territórios de origem. Essa articulação entre Tempo Escola e Tempo Comunidade é fundamental para o desenvolvimento de práticas educativas articuladas aos modos de vida dos povos do campo (CARVALHO; SILVA, 2018).

A fim de promover a articulação entre o Tempo Escola e o Tempo Comunidade, as LEdoCs utilizam instrumentos pedagógicos diversos ${ }^{4} \mathrm{em}$ seu processo de formação em alternância. Dentre os instrumentos pedagógicos da Licena, destaca-se o Projeto de Estudo Temático (PET), uma atividade de pesquisa proposta pelos educadores do curso a serem desenvolvidas pelos educandos durante o Tempo Comunidade com o objetivo de promover reflexões a partir do levantamento de informações sobre seus territórios de origem (UNIVERSIDADE FEDERAL DE VIÇOSA, 2019).

Embora os Instrumentos Pedagógicos não possam ser pensados separadamente, o PET teve um papel central para o desenvolvimento da Metodologia das Produções Narrativas, uma vez que ele

\footnotetext{
4 Especificamente em relação à Licena, alguns dos instrumentos pedagógicos utilizados são o Projetos de Estudo Temático, a Colocação em Comum, a Troca de Saberes, o Acompanhamento de Tempo Comunidade, o Embarque, o Espaço Aberto, o Licine, a Feira de Conhecimentos e o Desembarque.
} 
define o Eixo Temático que balizará as discussões de ensino, pesquisa e extensão tanto no TE quanto no TC durante um semestre letivo. O Eixo Temático adotado no segundo ano de formação da Licena foi "Territórios Educativos", sendo que o Tema Articulador do quarto período era "Produção de Conhecimento e Qualidade de Vida", a partir do qual foram orientadas as entrevistas e as produções narrativas.

A utilização dos instrumentos pedagógicos da alternância em diálogo com a entrevista narrativa tinha por objetivo reforçar a proposta original do Plano de Estudos, na qual os alternantes levantam informações vivenciais sobre o tema gerador proposto (GIMONET, 2007). Nesse sentido, guardam o objetivo de ampliar, aprofundar e reelaborar as informações iniciais, tal como proposto pela entrevista narrativa ao abordar as impressões dos sujeitos. Contudo, neste momento, se estabelece um processo dialógico que amplia - sem abandonar - a perspectiva subjetiva da construção do conhecimento. Em outras palavras, o processo de conhecer segue uma trajetória construtiva pessoal, mas à qual se oferecem possibilidades de sistematização a partir da incorporação de elementos necessários à sua formação docente.

Partindo desta concepção, vislumbra-se a possibilidade de desenvolver ações formativas derivadas dessa forma de narrar o mundo, de onde emerge uma ação política a partir da parcialidade dos saberes, de sua participação na produção de conhecimento e pelo estabelecimento de uma rede de comunicação entre estes atores locais e o saber acadêmico.

\section{CARACTERÍSTICAS DA METODOLOGIA DAS PRODUÇÕES NARRATIVAS}

A Metodologia das Produções Narrativas (MPN), no contexto de uma progressiva propagação de abordagens sobre as narrativas, busca diferenciar-se de interpretações discursivas nas quais o sujeito encontra-se diluído nas estratégias de interpretação da linguagem (MARTíNEZ-GUZMÁN; MONTENEGRO, 2014), sendo uma ferramenta metodológica desenvolvida para fomentar o papel ativo e construtivo do narrador.

Para tanto, a MPN ancora-se em referenciais como Mikhail Bakhtin e Donna Haraway. A influência de Bakhtin (1981) manifesta-se na natureza social e produtiva da enunciação, calcada em elementos concretos. Para ele, todas as formas de manifestação são fragmentos materiais da realidade em que determinados sujeitos estão imersos, são um universo de signos, que dentre outras possibilidades expressivas, podem se organizar sob a forma de narrativa. Por este motivo, a MPN caracteriza as narrativas como um dispositivo semiótico-material, ou seja, uma representação ancorada em situações concretas e produzida em situações dialógicas (PUJOL; MONTENEGRO, 2013).

A teoria dos Conhecimentos Situados de Haraway (1995) também é uma referência importante para a MPN. O conceito de experiência, base da teoria dos Conhecimentos Situados, valoriza o direcionamento sensivel dos saberes, dimensão abandonada pelo conhecimento científico tradicional. A experiência orienta as decisões sobre quais saberes são desejáveis e necessários. Os aspectos subjetivos da experiência são o ponto de partida na condução do processo de conhecer, uma vez que "por seu singular registro metodológico e ontológico, a perspectiva narrativa permite uma abordagem que envolve o pessoal e o político sobre a base da experiência 'encarnada' e a visão situada" 
(MARTINEZ-GUZMAN; MONTENEGRO, 2014, p. 116). O conhecimento buscado pela Metodologia das Produções Narrativas advém de relações de intersubjetividade, continuamente atualizada à luz da experiência entre sujeitos acadêmicos (entrevistadores) e não acadêmicos (narradores) (MONTENEGRO, 2003). Em diálogo com os paradigmas emancipatórios propostos por Santos (2007), a noção de experiência contribuiria para desconstruir uma noção totalizante e homogeneizante do saber, reforçando as tendências presentes neste momento de transformações radicais do conhecimento científico, social e político. Sua principal contribuição seria evidenciar a diversidade de saberes que emerge a partir das tentativas de explicar os fenômenos nos quais estamos envolvidos, mas também os elementos que permitem reconhecer um liame entre eles (HARAWAY, 2009).

Para a Metodologia das Produções Narrativas, os conhecimentos são produtos de uma relação parcial entre investigador e investigado, na qual, apesar da experiência compartilhada, não permite dizer de uma identidade entre elas. O narrador, a partir de sua experiência, constrói uma interpretação sobre o vivido, sobre sua intencionalidade e sobre os elementos históricos e contextuais do tema narrado. A interação entre entrevistador e narrador insere elementos específicos na narrativa daquele encontro a partir das perguntas e respostas apresentadas. O conhecimento produzido nesta relação é fruto de uma tensão entre semelhança e diferença na compreensão desta experiência e que busca ser desvelado neste processo de interação. Assim, este conhecimento é situado e, portanto, parcial (BALASCH; MONTENEGRO, 2003).

As experiências dos participantes da pesquisa na MPN são compreendidas como um conhecimento em construção que podem ser remanejadas e reinterpretadas a partir dos processos reflexivos e interativos provocados pelas narrativas. Em se tratando de sujeitos envolvidos nas ações de suas comunidades, espera-se que esta construção repercuta em suas ações e nas ações de seu grupo social (GOIKOETXEA, 2014).

A peculiaridade da proposta narrativa em termos gnosiológicos é a ausência de uma análise acadêmica que desvele seu significado a fim de legitimá-la. A narrativa, em si, representa uma perspectiva válida de interpretação, construída na interlocução entre entrevistador e narrador. Os pressupostos que orientam a ação do entrevistador são: a elucidação dialógica dos argumentos do narrador, a problematização das contradições presentes nos argumentos apresentados e o aprofundamento/esclarecimento em torno de afirmações generalistas e pouco claras. A narrativa resultante é um material com capacidade heurística em si.

Em seu processo de construção, a MPN é desenvolvida a partir de entrevistas nas quais se discutem as experiências dos entrevistados em uma dada temática, em geral, objeto de estudo de um grupo de pesquisa ou investigação em andamento. Pesquisador e entrevistado dialogam sobre diversos aspectos do fenômeno estudado, considerando que o participante, nessa interação, relata, revisita e reconstrói sua compreensão sobre tais experiências. Após cada sessão, o pesquisador redige uma narrativa sobre as principais ideias discutidas e a apresenta ao grupo de pesquisadores do qual faz parte. Com as questões levantadas pelo grupo, a narrativa será apresentada ao entrevistado. Os comentários e as questões apresentadas pelo pesquisador orientam a retomada da entrevista seguinte, sendo a narrativa anterior esclarecida, corrigida e/ou ampliada. (BALASCH; MONTENEGRO, 2003; MONCLUS, 2011). Esse processo pode se repetir segundo o interesse e disponibilidade de 
pesquisador e participante da pesquisa, partindo-se do princípio de que nenhuma versão conseguirá esgotar todas as possibilidades. Ao final, dispõem de um texto elaborado e validado conjuntamente entre pesquisador e entrevistado, com contribuições para os meios sociais dos participantes da pesquisa e a comunidade científica (BALASCH; MONTENEGRO, 2003). Partindo desses pressupostos, a finalidade da investigação não é chegar a uma teoria universal, mas "abrir os espaços de compreensão e produção de significados, dando ênfase aos efeitos que se depreendem do conhecimento produzido" (GOIKOETXEA, 2014, p. 131).

A utilização da MPN como estratégia pedagógica pressupunha que a narrativa produzida na interação entre pesquisador e entrevistado poderia ser considerada como o trabalho acadêmico do Projeto de Estudo Temático (PET), abordando a temática definida para aquele período, a saber, Territórios Educativos: Produção de Conhecimento e Qualidade de Vida. A única diferença entre a modalidade original de MPN e a utilizada nessa pesquisa foi que sua utilização como estratégia pedagógica pressupunha a redação da narrativa pelo próprio entrevistado.

\section{PRODUÇÕES NARRATIVAS DE UMA EDUCANDA DO CURSO DE LICENCIATURA EM EDUCAÇÃO DO CAMPO}

As narrativas construídas por Rosa ${ }^{5}$ estavam articuladas às atividades do PET, desenvolvido quando a educanda cursava o quarto período do curso de Licenciatura em Educação do Campo da Universidade Federal de Viçosa (Licena). O tema do PET era "Territórios Educativos: Produção de Conhecimento e Qualidade de Vida". Nas entrevistas narrativas, buscou-se identificar e analisar quais foram os espaços sociais vivenciados pela educanda que, em sua trajetória, contribuíram para sua formação como sujeito do campo.

No decorrer da primeira entrevista, Rosa destaca alguns aspectos da sua trajetória de vida pessoal e familiar por meio da apresentação dos modos de vida de seu pai e de sua mãe. Nesse contexto, a entrevistada relata que, principalmente durante a infância, os processos educativos não escolares foram fundamentais para sua formação, em especial sua participação junto a seus pais em atividades artísticas - como teatro, poesia e artesanato - e em agroecologia, como a produção agroecológica e de fitoterápicos, que a fizeram experienciar práticas sociais e culturais. Rosa viajou com seus pais por diversas regiões do Brasil realizando apresentações culturais em escolas, nas ruas e em espaços públicos. Segundo a entrevistada, essas experiências foram fundamentais para a sua constituição enquanto sujeito social, referenciando-a nas atividades que desenvolve nos dias atuais. Ela torna isso evidente em sua primeira narrativa:

[...] Meu pai e minha mãe são meus maiores mestres, trouxeram-me para o mundo e deixaramme o exemplo de cuidado pessoal com fitoterápicos. É como mamãe sempre me disse "olha filha, se precisar de um chá digestivo pode tomar um de alfavaca ou de manjericão". E assim ela me ensinou que existem antibióticos naturais como a tansagem, que é preciso curar o ser por completo e não somente o sintoma (doença). Meu pai também me ensinou inúmeras coisas, principalmente sobre arte. Hoje ando de perna de pau, de corda bamba, dou oficina de máscaras, conto histórias, e isso veio de vivências com ele [...] (ROSA).

\footnotetext{
${ }^{5}$ Nome fictício para preservar a identidade da participante da pesquisa.
} 
[...] A vida é a maior escola de todas, e como já dizia Guimarães Rosa "a vida é assim: esquenta e esfria, aperta e daí afrouxa, sossega e depois desinquieta. O que ela quer da gente é coragem." Assim foi a escola da vida no meu universo pessoal. Ter coragem pra enfrentar desafios recorrentes do dia-a-dia, como cuidar dos meus irmãos e auxiliar uma mãe solteira, guerreira e forte como todas as Marias desse pequeno grande mundo. A escola da vida foi e é pra mim o grande afã de uma filha de uma sociedade que, separada por classes, dita quem vai estudar em uma universidade pública, que teoricamente deveria ser acessível para todas e todos. [...]. (ROSA).

Destaca-se em sua narrativa, após a realização da primeira entrevista, um texto poético com experiências em espaços educativos não escolares, seu papel em seu processo formativo e em sua percepção e posicionamento ante o mundo. Nesses trechos de narrativa, ela revela aspectos destas experiências educativas junto à família com evidente investimento afetivo, sendo os mesmos retomados nas entrevistas seguintes, articulados a novas experiências de vida que são referenciais para sua trajetória de educadora. Ressalta, ainda, algumas das suas vivências em processos educativos escolares e suas perspectivas em relação aos princípios e objetivos da educação formal, apresentados no trecho a seguir.

\footnotetext{
O descaso com a educação brasileira é um fato recorrente. Inúmeras crianças e jovens são afetadas pela falta de recursos didáticos e físicos. Ainda hoje existem escolas que não tem energia elétrica e merenda escolar e, além desses casos extremos, existe o pior dos fatos que é a Escola Sem Partido, conteudista e manipuladora, que objetiva a formação de pessoas para o mercado de trabalho, reverberando em falta de metodologias, consciência crítica, política, social, ambiental e econômica. Esse é o modelo escolar predominante na sociedade brasileira e foi nele que eu estudei durante 17 anos. [...] (ROSA).
}

Nessa narrativa, Rosa descreve a escola como território educativo a partir de duas experiências: uma primeira experiência positiva, suplantada por uma outra experiência negativa. $\mathrm{O}$ último trecho dessa narrativa é a síntese de sua percepção prevalecente sobre sua experiência escolar: uma leitura negativa e estereotipada que voltará a ser discutida em entrevistas posteriores.

A narrativa redigida por Rosa, pela peculiaridade de uma trajetória repleta de mudanças de endereços e vivências com diferentes membros da família, apresentou uma significativa perda de informações e inconsistências factuais e cronológicas, considerando-se o que foi narrado na entrevista. Tais perdas de informação estão vinculadas, principalmente, à falta de detalhamento de seu percurso de vida e da sequência dos processos de transição entre os diferentes momentos que o compunham.

Considerando que as produções narrativas constituem parte de um processo formativo no qual a principal estratégia é esclarecer e aprofundar os fenômenos narrados, tornou-se necessário provocar reflexões sobre os processos de produção de conhecimento em torno do tema proposto para o PET Territórios Educativos: Produção de Conhecimento e Qualidade de Vida. Assim, após a leitura da narrativa e da transcrição da entrevista - utilizada como forma de recuperar conteúdos, uma vez que a narrativa apresentava-se muito aquém do que foi narrado oralmente - os pesquisadores elaboraram questões com o objetivo de aprofundar nos conteúdos narrados, buscando refletir junto a Rosa sobre as lacunas e as inconsistências em sua narrativa. Buscava-se, também, provocar reflexões na participante da pesquisa sobre como alguns acontecimentos influenciaram em sua trajetória e a auxiliaram na construção de sua percepção sobre o mundo.

Durante a segunda entrevista, Rosa pôde acrescentar elementos que elucidaram aspectos vivenciados durante sua trajetória escolar e os desafios vividos por ela para se adaptar à transferência 
de uma escola Municipal de Ensino Fundamental, situada na Chapada Diamantina (BA), para outra escola municipal onde concluiu o Ensino Fundamental, localizada em um distrito no interior do estado do Espírito Santo, a qual será chamada por Penha. À narrativa apresentada anteriormente, ela acrescenta:

\begin{abstract}
Lembro que no primeiro dia de aula estava chorando porque não queria ficar na escola da Penha. Nessa escola, a relação com os professores foi boa ao longo do tempo. Mas tem uns pontos negativos, tipo quando falavam que eu era filha de hippie. Eles falavam: "você é filha de hippie e quando você crescer, também vai ser hippie". Nossa, ficava em uma rejeição com isso. Este preconceito afeta. Eu falava que não iria ser hippie quando crescesse [...]. (ROSA).

[...] com cinco anos de idade, dei meus primeiros passos rumo a escola. Estudei em uma instituição pública em uma cidade da Chapada Diamantina (BA). Lá o ensino apresentava conteúdos de alfabetização, teatros, brincadeiras, vivências na comunidade e nós, alunos, ajudávamos nas tarefas da escola, como lavar nossos pratos após as refeições. Com o passar de um ano retornei com minha mãe e minha irmã para a Penha. Fui matriculada em uma escola pública, onde concluí o Ensino Fundamental. A educação formal apresentada lá era descontextualizada da realidade dos alunos, sendo que estes eram em sua grande maioria da zona rural ou do próprio distrito, que tem em torno de 300 habitantes. Essa escola onde estudei tinha como objetivo apresentar o conteúdo programático do livro didático destinado à instituição de três em três anos. A falta de recurso também limitava o aprendizado. Não existia quadra de esportes, hortas, ou variedades de livros interativos e informativos. (ROSA).
\end{abstract}

Comparando a escola situada na Chapada Diamantina, cujos processos educativos utilizam-se de elementos artísticos e culturais para complementar os processos formativos, Rosa destaca que a escola da Penha desconsiderava as práticas sociais, bem como os saberes e experiências sociais dos educandos, provocando-Ihe uma sensação de estranhamento e desaprovação. A mudança de escola evidencia um processo de ruptura, passando de uma perspectiva mais próxima ao seu universo vivencial familiar para uma prática pedagógica não apenas alheia a estes processos, mas que evidenciava preconceitos em relação ao seu modo de vida familiar. Rosa destaca, ainda, que os processos educativos escolares nesta escola, onde concluiu o Ensino Fundamental, não eram dialógicos e tampouco estabeleciam relações com as realidades vivenciadas pelos educandos.

[...]. Lembro que as aulas (na Penha) eram muito baseadas no livro didático, a gente até fala da educação bancária. Nós vemos no livro e tem aquele conteúdo que nem sempre vai dialogar com nossa realidade. $E$ de fato não dialogava, mas foi totalmente baseada porque a professora, por exemplo, de português, pegava um livro e ia falando: "vai fazer exercício e lê isso." Não foi a melhor educação do mundo, mas foi a que deu. Eu fiquei dos 6 aos 14 anos nessa escola. (ROSA).

A identificação de vivências contraditórias entre o processo de escolarização no Ensino Fundamental e o modo de vida contra hegemônico praticado por seus pais, fizeram Rosa apropriar-se desta última, como sujeito e como educadora. Tal posição assumida orientou sua trajetória para a busca por processos educativos dialógicos, capazes de articular os saberes, as culturas e as realidades vivenciadas pelos educandos em seus territórios educativos. É nesse contexto de busca por outras experiências educativas e de trabalho que Rosa se muda para Viçosa - MG, onde concluiu o Ensino Médio em uma escola estadual deste município.

A terceira entrevista realizada com Rosa buscou identificar, avaliar e complementar as informações sobre os espaços educativos vivenciados por ela ao se mudar para Viçosa -MG e compreender como se relacionavam com a diversidade e especificidade de suas experiências. Com 
isso, buscou-se evidenciar, dentre as experiências narradas sobre seus territórios educativos, aquelas que a participante da pesquisa julgava serem as mais significativas.

Durante a terceira entrevista, ficou evidente que as experiências prévias de Rosa encontraram afinidade com os grupos com os quais ela passou a desenvolver atividades em Viçosa - MG e que atuavam com a agroecologia. Seu primeiro contato ocorreu por meio do curso "Gaia Viçosa - Educação para a Sustentabilidade", promovido pelo Instituto Socioambiental de Viçosa (ISAVIÇOSA) ${ }^{6}$. Em sua narrativa, Rosa destaca que a participação neste curso possibilitou a ampliação de seus conhecimentos, dentre outras coisas, sobre temáticas relacionadas à agroecologia. Além disso, a participação neste curso possibilitou que Rosa conhecesse a Licena, à qual viria a ingressar pouco tempo depois. $\mathrm{O}$ ingresso na Licena ofereceu-lhe possibilidades para desenvolver suas experiências anteriores, ampliando-as a partir do aprendizado de metodologias participativas de base freiriana, vindo a ser uma inspiração para ela como educadora, capaz de promover processos educativos articulados às realidades vivenciadas por seus educandos, como pode ser observado no relato abaixo.

\begin{abstract}
A vida é uma ciranda, de giro em giro, sonho se realiza e vontade se concretiza. Meu sonho de passar na universidade e fazer um curso com boas metodologias de ensino e conteúdo progressista se realizou. Entrei na Licena em 2017, e, desde então, venho descobrindo nesse girar da vida a riqueza que é o planeta Terra e o quanto temos que respeitá-lo, estabelecendo inter-relações e reconectando nossa humanidade e valores éticos. [...]. Desde que entrei no curso venho aprendendo sobre didática, metodologias freirianas, saberes populares e ancestrais e esses conhecimentos reforçam em mim a vontade de dar aula, de ensinar e, principalmente, de aprender com os educandos. (ROSA).
\end{abstract}

O ingresso na Licena colocou Rosa em contato com processos educativos que, em sua perspectiva, eram dialógicos, estimulavam a promoção de práticas formativas por meio de metodologias participativas capazes de articular os saberes e as práticas sociais e culturais das realidades vivenciadas pelos educandos aos conhecimentos escolares e acadêmicos. As atividades desenvolvidas no âmbito da Licena, pode-se dizer, orientaram uma perspectiva educacional latente desde suas experiências educacionais no ensino fundamental, definindo um rumo em sua formação para o exercício da docência.

O ingresso na Licena possibilitou-lhe, ainda, interagir com sujeitos oriundos de diferentes contextos sociais, assim como organizações sociais e sindicais diversas, como o Centro de Tecnologias Alternativas da Zona da Mata (CTA/ZM); os Sindicatos dos Trabalhadores Rurais; o Movimento dos Trabalhadores Rurais Sem Terra (MST); as Escolas Família Agrícola (EFAs); a Rede Quilombola; a Comissão Pastoral da Terra (CPT); entre outros. Dentre as organizações sociais vivenciadas durante o processo formativo na Licena, Rosa destaca o CTA/ZM, uma instituição voltada para ações para difundir a Agroecologia na Zona da Mata de Minas Gerais desde 1987. Um dos projetos desenvolvidos pelo CTA/ZM é o Curupira que, desde 2006, realiza atividades em escolas do campo e periurbanas sobre preservação ambiental e o desenvolvimento de práticas agroecológicas por meio da articulação entre arte, cultura e educação (CORTES, SANTOS, CUNHA, 2017).

A participação de Rosa no Projeto Curupira permitiu a ela desenvolver atividades educativas em escolas de educação básica, abordando saberes sobre arte e cultura popular. Segundo sua

${ }^{6}$ O curso "Gaia Viçosa - Educação para a Sustentabilidade" aconteceu nos meses de outubro e dezembro de 2015 e de fevereiro e abril de 2016. 
narrativa, essa experiência permitiu-lhe lançar mão de suas vivências junto a seu pai e sua mãe articulando-as às metodologias participativas aprendidas na Licena.

[...]. Então, trabalhar no CTA/ZM é retomar a mesma coisa que fazia com o meu pai, pois acho que minha sina é viver trabalhando em escola com arte e cultura. Acho que tem essa relação com o passado e das coisas que vivi de acordo com as escolhas que estou fazendo de entrar na Licena e entrar no CTA/ZM. O meu território educativo é o CTA/ZM porque a gente trabalha com essa questão da educação. Arte e educação nas escolas e levando a questão da agroecologia. (ROSA).

A terceira e última versão da narrativa de Rosa evidencia que o Projeto Curupira é considerado, hoje, seu principal território educativo, por possibilitar, em um único lugar, a articulação de experiências e saberes desenvolvidos em diferentes momentos e espaços de sua trajetória. Não obstante, a possibilidade de acolhimento das expressões subjetivas de Rosa pela Licena demonstram a importância de um espaço acadêmico atento e permeável à diversidade de saberes dos quais seus estudantes são portadores.

Neste sentido, a Metodologia das Produções Narrativas encontrou na Licena uma organização e princípios convergentes para que se apresentasse como uma estratégia pedagógica capaz de provocar em Rosa a expressão, a reflexão e a compreensão do tecido no qual sua trajetória vinha se constituindo.

Observa-se a partir do estudo de caso apresentado, que a Metodologia das Produções Narrativas tem importantes contribuições a dar no processo formativo de futuros educadores que atuarão no campo, não apenas pela identidade que guarda em torno de princípios pedagógicos que valorizam a experiência vivida, o processo reflexivo sobre a mesma e o estímulo à produção de conhecimentos contextualizados. Esta concepção de aprendizagem é inerente à perspectiva da Educação do Campo, podendo trazer, enquanto estratégia pedagógica, contribuições significativas para as LEdoCs.

\section{ALGUMAS CONSIDERAÇÕES}

Com o objetivo de formar educadores para atuarem em processos educativos escolares e na gestão de espaços educativos não escolares no campo, as LEdoCs são orientadas por um regime de formação em alternância, ou seja, um modelo educacional que organiza os processos formativos entre os espaços escolares (Tempo Escola) e os espaços comunitários (Tempo Comunidade). Considera-se que o conhecimento é produzido a partir do diálogo entre estes dois espaços, instrumentalizado por ferramentas pedagógicas específicas. Dentre elas destaca-se o Projeto de Estudos Temáticos (PET), uma orientação de pesquisa que o estudante leva para o Tempo Comunidade com o objetivo de promover reflexões sobre os processos sociais, culturais, ambientais, educacionais e econômicos em seus territórios de origem.

Este artigo buscou avaliar, a partir do estudo de caso de Rosa, as possíveis contribuições da Metodologia das Produções Narrativas (MPN) para o desenvolvimento do PET adotado pelo curso, cuja temática era Territórios Educativos: Produção de Conhecimento e Qualidade de Vida. 
Considerou-se que a MPN se orientaria por princípios pedagógicos similares aos propostos pelas LEdoCs e das Alternâncias Educativas. A MPN considera que todo indivíduo, ao narrar, parte de uma perspectiva parcial sobre as realidades em que vive, permitindo-lhe evidenciar as especificidades culturais, os processos educativos e as práticas sociais existentes nos contextos sociais investigados.

As narrativas produzidas a partir de três entrevistas realizadas junto a Rosa permitiram verificar que as informações produzidas, narrativa após narrativa, descortinavam um emaranhado de experiências ainda não refletidas pela participante da pesquisa sobre sua trajetória. Na primeira entrevista narrativa, verificou-se que as vivências mais significativas de suas primeiras experiências educativas emergiam, ainda que de forma pontual, sintéticas e pouco sistematizadas. A segunda entrevista abordou as lacunas deixadas pela primeira, permitindo adensar suas narrativas no detalhamento e aprofundamento das relações entre os eventos narrados. A terceira entrevista, que buscava articular as vivências com os territórios educativos atuais, evidenciou enlaces que atribuiriam à sua trajetória uma consistência em torno de princípios e expectativas em relação à educação, à agroecologia e a um modo de ser contra hegemônico.

As análises relacionadas aos usos da MPN como estratégia pedagógica para uma educanda do curso de Licenciatura em Educação do Campo permitiram concluir que, ao partir das experiências subjetivas, tal metodologia adequa-se e traduz as temáticas investigadas para ela, potencializando sua apropriação e reflexão sobre os eventos narrados. Esta conclusão pode ser observada nas narrativas realizadas junto a Rosa, ao favorecerem a sistematização de suas experiências e o fortalecimento de suas escolhas a partir de sua participação na pesquisa.

Embora a utilização da MPN já tivesse sido aplicada a outros educandos da Licena (SANTOS; SILVA, 2019) com o objetivo de identificar as suas contribuições como uma estratégia pedagógica para o curso, a situação de Rosa traz como diferencial uma trajetória peculiar de descontinuidades entre lugares e pessoas em diferentes territórios educativos.

A narrativa de Rosa evidencia, portanto, a importância de um curso que ofereça possibilidades de diálogos com a diversidade de experiências de sujeitos sociais diversos, acolhendo e fortalecendo o percurso formativo de seus educandos a partir delas. Fundamentalmente, a narrativa de Rosa evidencia a contribuição da MPN ao permitir ao sujeito, para além de realizar uma síntese narrativa a partir da releitura dos contextos vividos e suas intencionalidades como sujeito, legitimar a identidade e os modos de agir dos povos do campo.

\section{REFERÊNCIAS}

1. BAKHTIN, Mikhail. Marxismo e Filosofia da Linguagem. São Paulo: Hucitec, 1981.

2. BALASCH, Marcel; MONTENEGRO, Marisela. Una propuesta metodológica desde la epistemología de los conocimientos situados: Las producciones narrativas. Encuentros en Psicología Social, v. $1, \quad$ n. ${ }^{\circ} \quad 3,44 \quad-\quad 48,2003$. Disponível em: 
<https://www.academia.edu/762651/Una_propuesta_metodológica_desde_la_epistemología_de_los _conocimientos_situados_Las_producciones_narrativas > Acesso em: 01/10/2019.

3. CARVALHO, Josiane das Graças; SILVA, Lourdes Helena. Alternance in the formation of countryside educators: looking for markers in the academic productions and social representations of education students. Revista tempos e espaços em educação, São Cristóvão, v. 11, n. 26, p. 339350, 2018. Disponível em: <https://seer.ufs.br/index.php/revtee/article/view/7270/pdf> Acesso em: 23/09/2019. http://dx.doi.org/10.20952/revtee.v11i26.7270.

4. CORTES, Maria de Oliveira; SANTOS, Amanda Melissa; CUNHA, Adeline Ribeiro. Construção do conhecimento agroecológico no ambiente escolar: o Projeto Curupira na Zona da Mata mineira. Cadernos de Agroecologia, v. 12, n. ${ }^{\circ}$ 1, 2017. Disponível em: <http://revistas.abaagroecologia.org.br/index.php/cad/article/view/22369/12829> Acesso em: 02/10/2019.

5. GIMONET, Jean-Claude. Praticar e compreender a pedagogia da alternância dos CEFFAs. Petrópolis, RJ: Vozes, 2007.

6. GOIKOETXEA, Itziar Gandarias. Tensiones y distensiones en torno a las relaciones de poder en investigaciones feministas con Producciones Narrativas. Quaderns de Psicologia, vol. 16, no. 1, 127-140, 2014. https://doi.org/10.5565/rev/qpsicologia.1210.

7. HARAWAY, Donna. Manifesto Ciborgue: Ciência, tecnologia e feminismo-socialista no final do século XX, In: HARAWAY, Donna; KUNZRU, Hari; TADEU, Tomaz. Antropologia do Ciborgue: as vertigens do pós-humano. 2a. Edição. Belo Horizonte, Autêntica, 2009.

8. HARAWAY, Donna. Ciencia, Cyborgs y Mujeres: la reinvención de la naturaleza. Madrid, Cátedra, 1995.

9. MARTÍNEZ-GUZMÁN, Antar; MONTENEGRO, Marisela. La Producción de Narrativas como Herramienta de Investigación y Acción sobre el Dispositivo Sexo/Género: Construyendo nuevos relatos. Quaderns de Psicología, 2014, vol. 2016, no. 1, pp. 111-125. https://doi.org/10.5565/rev/qpsicologia.1210.

10. MOLINA, Mônica Castagna e SÁ, Lais Mourão. Licenciatura em Educação do Campo. In.: CALDART, Roseli Salete; PEREIRA, Isabel Brasil; ALENTEJANO, Paulo; FRIGOTTO, Gaudêncio (Org.) Dicionário da Educação do Campo. Rio de Janeiro, São Paulo: Escola Politécnica de Saúde Joaquim Venâncio, Expressão Popular, 2012.

11. MOLINA, Mônica Castagna. Contribuições das Licenciaturas em Educação do Campo para as políticas de formação de educadores. Educação \& Sociedade, Campinas, v. 38, n. ${ }^{\circ}$ 140, p.587-609, 
2017. Disponível em: <http://www.scielo.br/pdf/es/v38n140/1678-4626-es-38-140-00587.pdf> Acesso em: 01/10/2019. https://doi.org/10.1590/es0101-73302017181170.

12. MOLINA, Mônica Castagna. Expansão das licenciaturas em Educação do Campo: desafios e potencialidades. Educar em Revista, Curitiba v. 31, n. 55, p. 145-166, 2015. Disponível em: <http://www.scielo.br/pdf/er/n55/0101-4358-er-55-00145.pdf>. Acesso em: 27/09/2019. https://doi.org/10.1590/0104-4060.39849.

13. MOLINA, Mônica Castagna; ANTUNES-ROCHA, Maria Isabel. Educação do Campo: história, práticas e desafios no âmbito das políticas de formação de educadores - reflexões sobre o PRONERA e o PROCAMPO. Revista Reflexão e Ação, Santa Cruz do Sul, v. 22, n. 2, p.220-253, 2014. Disponível em: <https://online.unisc.br/seer/index.php/reflex/article/view/5252/3689> Acesso em: 01/08/2019. http://dx.doi.org/10.17058/rea.v22i2.5252.

14. MOLINA, Mônica Castagna; SÁ, Laís. Mourão. A Licenciatura em Educação do Campo da Universidade de Brasília: Estratégias Político-Pedagógicas na Formação de Educadores do Campo. In: MOLINA, Mônica Castagna; SÁ, Laís. Mourão. (Orgs.) Licenciatura em Educação do Campo: Registros e Reflexões a partir das Experiências Piloto. - Belo Horizonte: Autêntica Editora, 2011. p.35-61.

15. MONCLUS, Pamela Gutiérrez. Terapia Ocupacional: Una disciplina para la autonomía. Prácticas y discursos de Gubernamentalidad y subjetivación en torno a una ciencia emergente. 2011. $368 f$. Tese (Doctorado em Psicología Social). Universidad Autónoma de Barcelona, Barcelona.

16. MONTENEGRO, Marisela. Conocimiento Situado: Un Forcejeo entre el Relativismo Construccionista y la Necesidad de Fundamentar la Acción. Revista Interamericana de Psicología, n. 37, v.2, 2003.

17. PUJOL, Joan; MONTENEGRO, Marisela. Producciones narrativas: una propuesta teórico-práctica para la investigación narrativa. In: NOCETTI, M.T. (org) Coloquios de investigación cualitativa: desafíos en la investigación como relación social. Córdoba, Socialex, 2013. Paulo: Boitempo, 2007. protagonismo dos movimentos sociais do campo na instituição de políticas públicas e a Licenciatura em Educação do Campo na UnB. Brasília: Líber Livro, 2012. 
20. SANTOS, Marcelo Loures dos Santos; SILVA, Diego Gonzaga Duarte da Silva. Contribuições da metodologia das produções narrativas na licenciatura em educação do campo. Educação em Perspectiva, Viçosa, v. 10, p. 1 - 14, 2019. https://doi.org/10.22294/eduper/ppge/ufv.v10i0.8246.

21. UNIVERSIDADE FEDERAL DE VIÇOSA. Instrumentos Pedagógicos - Curso de Licenciatura em Educação do Campo - Ciências da Natureza. Viçosa, Minas Gerais, 2019. Disponível em: <http://www.educacaodocampo.ufv.br/wp-content/uploads/2019/04/instrumentos_pedagogicos.pdf> Acesso em: 23/09/2019.

\section{Marcelo Loures dos Santos}

Psicólogo pela UFMG (1994); mestre em psicologia social pela USP/USP (1999); doutor pela PUCCAMP (2009); pós-doutorado na Universidad Autònoma de Barcelona (2015).

\section{Diego Gonzaga Duarte da Silva}

Mestre em Educação pela Universidade Federal de Viçosa - UFV (2018). Licenciado em Geografia pela UFV (2015). Pedagogo pela Universidade de Franca (2019). Atualmente é Professor de Magistério Superior Substituto, vinculado ao Departamento de Educação da UFV, atuando no Curso de Licenciatura em Educação do Campo (LICENA).

\section{Como citar este documento:}

SANTOS, Marcelo Loures; SILVA, Diego Gonzaga Duarte da. Narrativa e trajetória camponesa: estudo de caso em um curso de licenciatura em Educação do Campo. Reflexão e Ação, Santa Cruz do Sul, v. 28, n. 2, jun. 2020. ISSN 1982-9949. Disponível em: $<$ https://online.unisc.br/seer/index.php/reflex/article/view/14364>. Acesso em: doi:https://doi.org/10.17058/rea.v28i2.14364. 